\title{
Concurrence of primary pulmonary malignant melanoma with invasive pulmonary adenocarcinoma: a case report
}

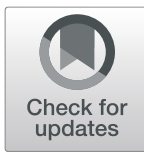

\author{
Luhuan Yang ${ }^{1 \dagger}$, Yunhong Lei ${ }^{1 \dagger}$, Rong Zhang ${ }^{1}$, Yufei Liu ${ }^{2}$, Wenli Dai ${ }^{3}$, Fei Tian ${ }^{1}$ and Jinglan Liu ${ }^{1 *}$
}

\begin{abstract}
Background: Primary pulmonary malignant melanoma (PPMM) is an extreme rarity in clinic practice, accounting for only $0.01 \%$ of all primary pulmonary tumors. And its diagnosis should meet clinical and pathological diagnosis criteria in addition to excluding the possibility of metastatic melanoma. The mainstay of treatment is surgery. The concurrence of primary pulmonary malignant melanoma and invasive pulmonary adenocarcinoma has not been reported before.

Case presentation: Herein we report the case of a 39-year-old woman who was asymptomatic and accidently found to have the concurrence of PPMM with invasive pulmonary adenocarcinoma. Before considering the diagnosis of primary pulmonary malignant melanoma, a systemic positron emission tomography-computed tomography (PET-CT) was done to excluding primary tumor metastasis from other sites. The pathological biopsy proved that two lesions in the right middle lobe were invasive pulmonary adenocarcinomas and the mass in the right lower lobe was malignant melanoma. She underwent right middle and lower lobectomy of the lung with mediastinal and hilar lymph dissection. She refused adjuvant chemotherapy, genetic molecular testing or immunotherapy. Fifteen months later she had brain metastasis. Then she received brain radiotherapy and underwent follow-up at the outpatient clinic regularly.
\end{abstract}

Conclusions: We experienced a case of concurrent PPMM and invasive pulmonary adenocarcinoma. The patient reported here is the first case of primary pulmonary malignant melanoma combined with invasive pulmonary adenocarcinoma. This patient remained disease-free 15 months after lung surgery.

Keywords: Malignant melanoma, Adenocarcinoma, Concurrence, Primary lung tumor

\section{Background}

Malignant melanoma (MM) is a malignant neoplasm of the melanocytes, usually arising from the skin. But it may also occur in other mucosal sites and organs [1-3]. Primary pulmonary malignant melanoma (PPMM) is extremely rare as only 51 cases have been reported since 1916 [2, 4]. The concurrence of PPMM and pulmonary adenocarcinoma has hardly been reported so far. Herein,

\footnotetext{
* Correspondence: yichanghospital@163.com

†Luhuan Yang and Yunhong Lei contributed equally to this work. 'Department of Emergency and Critical Care Medicine, The First College of Clinical Medical Science, Three Gorges University, Yichang Central People's Hospital, Yiling Road 183, Yichang City 443003, Hubei Province, China Full list of author information is available at the end of the article
}

we present a special case who had concurrent PPMM and invasive pulmonary adenocarcinoma. And then the PPMM-related literature was reviewed.

\section{Case presentation}

A 39-year-old woman with pulmonary space occupying lesions for 6 months was admitted to our hospital on January 02, 2018. She was firstly found to have pulmonary multiple nodules (maximum diameter $1.3 \mathrm{~cm}$, in the right lower lobe) on the chest computed tomography (CT) 6 months before. And 3 days before admission, her chest $\mathrm{CT}$ revealed the lesion in the lower lobe grew to $1.5 \mathrm{~cm}$. The positron emission tomography-computed tomography (PET-CT) showed the nodule in the right

\section{$\triangle B M C$}

(c) The Author(s). 2020 Open Access This article is licensed under a Creative Commons Attribution 4.0 International License, which permits use, sharing, adaptation, distribution and reproduction in any medium or format, as long as you give appropriate credit to the original author(s) and the source, provide a link to the Creative Commons licence, and indicate if changes were made. The images or other third party material in this article are included in the article's Creative Commons licence, unless indicated otherwise in a credit line to the material. If material is not included in the article's Creative Commons licence and your intended use is not permitted by statutory regulation or exceeds the permitted use, you will need to obtain permission directly from the copyright holder. To view a copy of this licence, visit http://creativecommons.org/licenses/by/4.0/ The Creative Commons Public Domain Dedication waiver (http://creativecommons.org/publicdomain/zero/1.0/) applies to the data made available in this article, unless otherwise stated in a credit line to the data. 
lower lobe had abnormal metabolism increase, which was different from the multiple nodules in the right middle lobe (Fig. 1a). And the PET-CT suggested no other possibility for a primary tumor lesion site.

The patient had no clinical symptoms. She denied any past history of smoking, skin or ocular lesions. A comprehensive physical examination was performed on admission. Her axillary temperature was $36.6^{\circ} \mathrm{C}$, blood pressure was $116 / 76 \mathrm{mmHg}$, pulse rate was 78 beats per minute, respiratory rate was 20 per minute, and oxygen saturation was $100 \%$ at room air. Her blood routine test, liver function test, electrolyte and renal function test, and lung cancer markers including Carcinoembryonic antigen (CEA), neuron-specific enolase (NSE), squamous cell carcinoma (SCC), CYFRA21-1 were all within the normal range, as were thyroid function test, coagulation function test, and pulmonary function test. The rapid test screening results for HIV, hepatitis B, and syphilis were negative. No abnormality was seen in her electrocardiogram. After excluding surgical contraindications, she underwent thoracoscopic resection of lung nodules under general anesthesia. During operation, two small nodules (around $0.3 \mathrm{~cm}$ in diameter) in the right middle lobe and a round, solid mass $(2 \mathrm{~cm}$ in diameter) in the right lower lobe were removed and sent for frozen section histology. The intra-operative frozen section histology showed two small nodules in the middle lung indicated adenocarcinoma, and the nodules of the lower lung were solid short fusiform epithelioid cell nest with large hemosiderin deposition, which was considered to be non-small cell carcinoma. Then the patient converted to thoracotomy, and underwent right middle and lower lobectomy of the lung with mediastinal and hilar lymph dissection.

Four days later, the final pathological biopsy proved that two lesions in the right middle lobe of the lung were invasive pulmonary adenocarcinomas which consisted of a mixture of acinar and papillary type. The mass in the right lower lobe consisted of solid short fusiform epithelioid cell nest with large hemosiderin deposition. No tumor cells were detected in the four groups of dissected lymph nodes. Immunohistochemical (IHC) staining of the tumor in the right lower lobe was positive for human melanoma black-45 (HMB-45), Melan-A, and Ki-67 (hot spot 70\%), Vimentin, S-100 protein, CgA, CDp56, whereas staining for cytokeratin (CK5/6, CK7), CD68, P63, TTF-1, P40, Napsin A, Syn, PCK [AE1/AE3] and EMA were negative (Fig. 2). Since the result of histological examination highly suggested MM and CT showed no other possibility for a primary tumor lesion site, the patient's tumor in the right lower lobe was diagnosed as PPMM. The final diagnosis of the patient was PPMM combined with invasive pulmonary adenocarcinoma.

She refused adjuvant chemotherapy, genetic molecular testing and immunotherapy, and was discharged after recovering from the surgery. Fifteen months after the pulmonary resection, she felt dizzy and headache. Then she underwent brain magnetic resonance imaging (MRI) and chest CT. The MRI showed she had a brain metastasis (Fig. 3). She received whole-brain radiotherapy at $3 \mathrm{~Gy}$

\section{a}

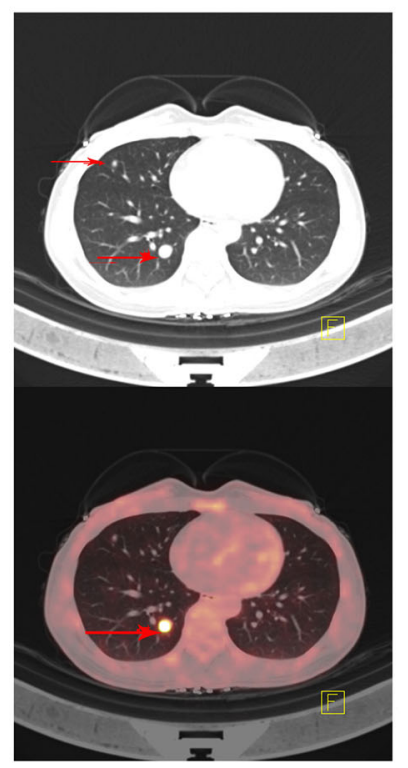

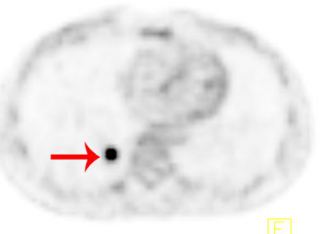

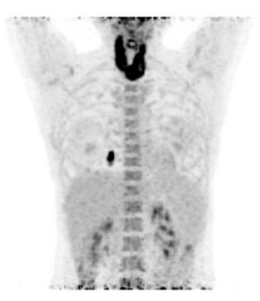

E: b
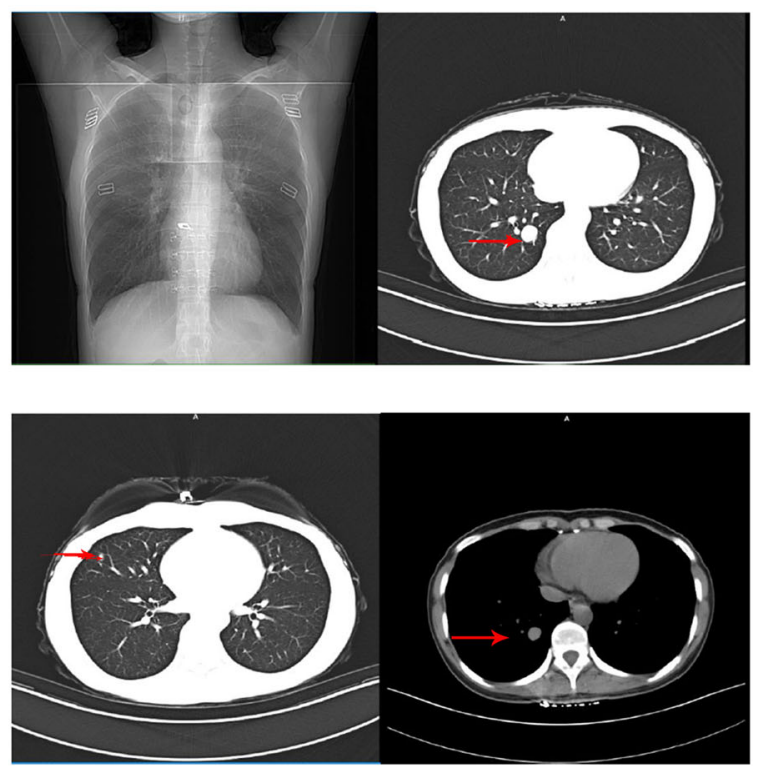

Fig. 1 a PET-CT revealed multiple nodules in the right middle lobe of lung and a nodule with abnormal metabolism increase in the right lower lobe; $\mathbf{b}$ Chest CT showed the tumor's size in the right lower lobe was increased 

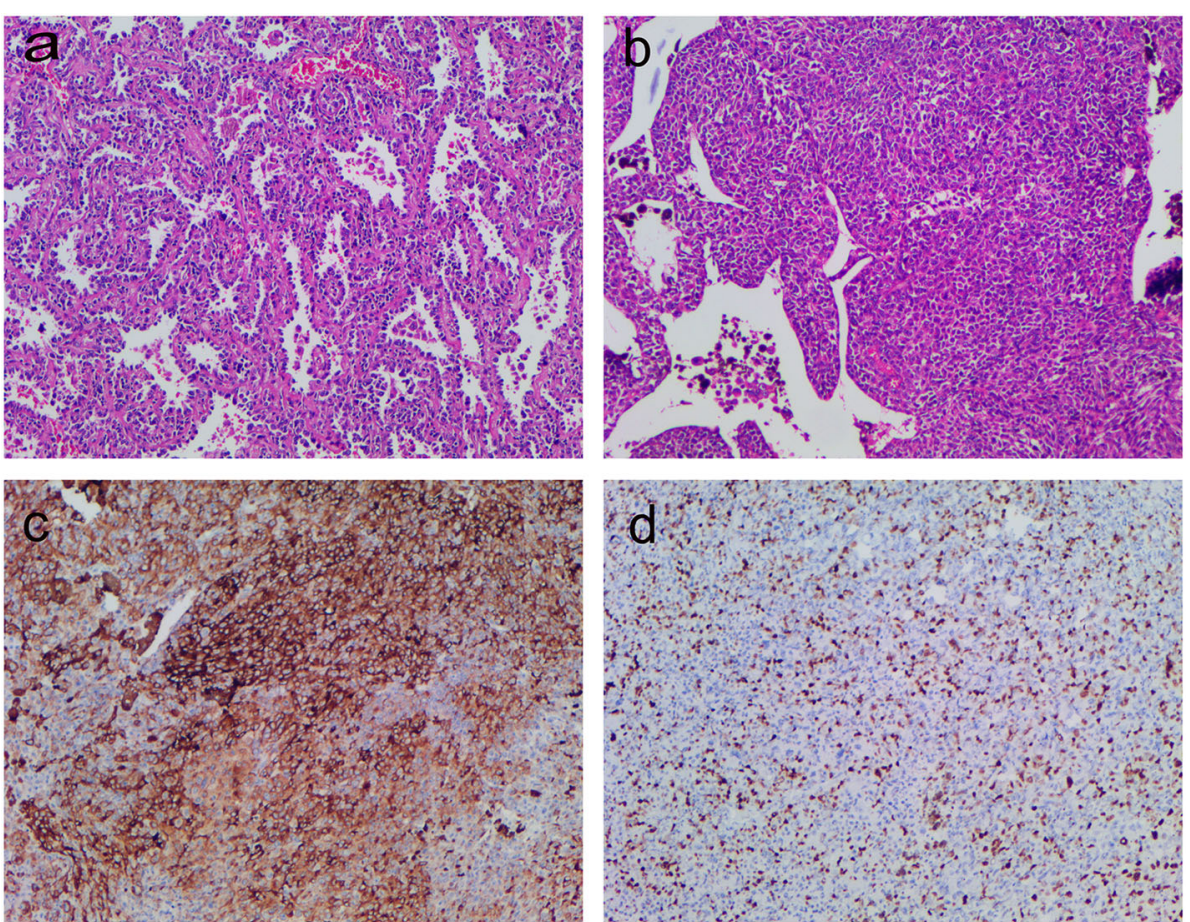

Fig. 2 a Pathological section biopsy showing infiltration by lung adenocarcinoma cells with acinar and papillary mixed type (hematoxylin and eosin staining $100 \mathrm{x}$ ); b Pathological section biopsy showing infiltration by solid short fusiform epithelioid cell nests containing melanin pigmentation from the lung lesion (100x); $\mathbf{c}$ Immunohistochemical expression of HMB-45 in neoplastic cells (DAB, magnification 100x). d Immunohistochemical expression of Ki-67 in neoplastic cells (DAB, magnification 100x)

each day, for a total dose of $30 \mathrm{~Gy} / 10 \mathrm{f}$, together with localized radiotherapy for craniocerebral lesions with a total dose of $12.5 \mathrm{~Gy} / 5 \mathrm{f}$. Then she was discharged and underwent follow-up at the outpatient clinic regularly.

\section{Discussion}

There are about 160,000 cases of newly diagnosed malignant melanoma every year throughout the world, with approximately 41,000 melanoma-related deaths annually [1]. $90 \%$ of malignant melanomas arise from the skin.
The neoplasm can also develop in the mucosal area, including the eye, oral mucosa, genital and perianal areas, esophagus, larynx, vagina and liver, etc. [5-7]. The pulmonary malignant melanomas are common metastatic lesions from the skin or ocular tumors [8]. PPMM is exceedingly rare, which accounts for only $0.01 \%$ of all primary pulmonary tumors $[9,10]$.

Kyriakopoulos et al. demonstrated the median age of PPMM was 59.1 years old (range from 29 to 90) [2, 11]. There were 21 men and 19 women in the population.
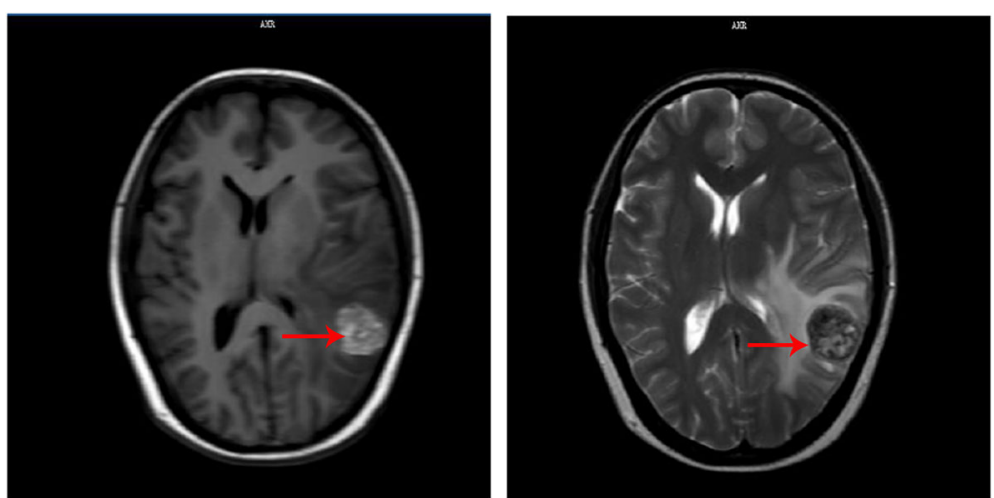

Fig. 3 Brain-enhanced magnetic resonance showed that the left temporal lobes showed nodular high-low mixed signal, with a diameter of about $2.6 \mathrm{~cm}$. Large edema was seen around the lesion, with the left lateral ventricle compressed and the midline structure shifted to the right 
Although cigarette smoking is considered as the incentive factor for lung cancers, smoking history was not found to be correlated with the development of PPMM. The common clinical manifestations include cough, hemoptysis, thoracalgia, difficult breathing, or weight loss. About 30\% of patients are asymptomatic and the lesion was discovered accidentally by chest imaging examination [12].

Since PPMM is an exceptionally rare tumor, metastasic melanoma from the skin or other organs should be carefully ruled out in these conditions [13, 14]. PPMM was diagnosed according to clinical and pathological criteria $[9,11,15]$. The clinical diagnosis criteria were as follows: a central and solitary tumor in the lung; no previous excision history of a cutaneous, mucous membrane, or ocular lesion; no melanoma in the other organs at diagnosis. The pathological criteria comprise immunohistochemical staining of S-100 and HMB-45, evidence of junctional changes including "dropping off" or "nesting" arranged in fascicles, and invasion of melanoma cells into the bronchial epithelium. Our case met the above criteria for diagnosing PPMM.

Lobectomy or pneumonectomy with lymph node dissection is the main treatment for localized pulmonary malignant melanoma [11, 16, 17]. Different types of chemotherapy and immunotherapy as well as radiotherapy have been attempted for MM patients, but no postoperative adjuvant therapy has a good effect on PPMM patients $[11,18]$. About 40 to $60 \%$ of skin melanomas carry BRAF gene mutations (V600E), which causes downstream signals continuous activation through the MAPK pathway $[2,13$, 19]. The FDA approved a range of BRAF inhibitors, including vemurafenib and dabrafenib, as well as MEK inhibitor [20-22]. With the development of immunotherapy in last few years, the FDA approved anti- PD-1 antibodies nivolumab and pembrolizumab for treating metastatic cutaneous melanoma in 2014 [11, 23]. Targeted therapy needs to evaluate the expression of tumor PD-L1.

Our patient showed 2 lesions in the middle lobe and 1 lesion in the right lower lobe. The lesion in the right lower lobe proved to be PPMM by pathological biopsy and immunohistochemical (IHC) staining. The lesions in the right middle lobe turned out to be invasive pulmonary adenocarcinoma by pathological biopsy, with typical a mixture of acinar and papillary type. There are several cases of synchronous primary melanoma and adenocarcinoma in digestive system reported. Yet there have been no similar case reports in the lung so far. The treatment of PPMM is still controversial, and the combination of adenocarcinoma makes the treatment more difficult.

The overall outcome of primary pulmonary malignant melanoma was very dismal and $65 \%$ of patients survived up to 18 months. Only two patients survived for a long time (10 and 11 years, respectively) [2]. As with other types of tumors, a better prognosis can be obtained through early discovery. Some patients were diagnosed unexpectedly by chest imaging without any clinical symptoms [2, 24]. This was the case with our patient. She didn't exhibit any respiratory tract symptom. The tumor was discovered accidentally by chest imaging examination. Fifteen months after the pulmonary resection, she was found to have a brain metastasis and underwent brain radiotherapy. It has been 22 months since she underwent the surgery, and she is on regular follow-up till now. Maybe the combination of adenocarcinoma accelerated the progression of her disease, which is unclear.

\section{Conclusion}

PPMM is exceedingly rare. Currently, surgery is the primary treatment for local PPMM. In this paper we showed the first case of concurrent melanoma and adenocarcinoma in the lung. And the patient remained disease-free 15 months after lung surgery.

\section{Abbreviations}

MM: Malignant melanoma; PPMM: Primary pulmonary malignant melanoma; $\mathrm{CT}$ : Computed tomography; PET-CT: Positron emission tomographycomputed tomography

\section{Acknowledgements}

Not applicable.

\section{Authors' contributions}

Luhuan Yang drafted the manuscript, Yunhong Lei performed the document retrival and designed the article structure, Zhang Rong revised the manuscript. Yufei Liu and Wenli Dai provided the pathological data and imaging data. Fei Tian was responsible for image layout. Jinglan Liu provided academic advice. All authors have read and approved the final manuscript.

\section{Funding}

None of the authors have any funding to disclose.

\section{Availability of data and materials}

All data generated or analyzed during this study are included in this published article.

Ethics approval and consent to participate

All procedures used in this research were approved by the Ethics Committee of the National Hospital Organization.

\section{Consent for publication}

Written informed consent was obtained from the patient for the publication of this case report and any accompanying images. A copy of the written consent form is available for review by the Editor-in-Chief of this journal.

\section{Competing interests}

The authors declare that they have no competing interests.

\section{Author details}

${ }^{1}$ Department of Emergency and Critical Care Medicine, The First College of Clinical Medical Science, Three Gorges University, Yichang Central People's Hospital, Yiling Road 183, Yichang City 443003, Hubei Province, China.

${ }^{2}$ Department of Pathology, The First College of Clinical Medical Science, Three Gorges University, Yichang Central People's Hospital, Yichang City 443003, Hubei Province, China. ${ }^{3}$ Department of Nuclear Medicine, The First College of Clinical Medical Science, Three Gorges University, Yichang Central People's Hospital, Yichang City 443003, Hubei Province, China. 
Received: 5 November 2019 Accepted: 17 March 2020

Published online: 26 March 2020

\section{References}

1. Markovic SN, Erickson LA, Rao RD, Weenig RH, Pockaj BA, Bardia A, et al. Malignant melanoma in the 21st century, part 1: epidemiology, risk factors, screening, prevention, and diagnosis. Mayo Clin Proc. 2007;82(3):364-80.

2. Shi $Y$, Bing $Z, X u X, C$ Cui $Y$. Primary pulmonary malignant melanoma: case report and literature review. Thorac Cancer. 2018;9(9):1185-9.

3. Siegel R, Ma J, Zou Z, Jemal A. Cancer statistics, 2014. CA Cancer J Clin. 2014;64(1):9-29.

4. Gong L, Liu XY, Zhang WD, Zhu SJ, Yao L, Han XJ, et al. Primary pulmonary malignant melanoma: a clinicopathologic study of two cases. Diagn Pathol. 2012;7:123.

5. Gong L, Li YH, Zhao JY, Wang XX, Zhu SJ, Zhang W. Primary malignant melanoma of the liver: a case report. World J Gastroenterol. 2008;14(31):4968-71.

6. Lewis MG, Martin JA. Malignant melanoma of the nasal cavity in Ugandan Africans. Relationship of ectopic pigmentation. Cancer. 1967;20(10):1699-705.

7. Gorenstein LA, Putnam JB, Natarajan G, Balch CA, Roth JA. Improved survival after resection of pulmonary metastases from malignant melanoma. Ann Thorac Surg. 1991;52(2):204-10.

8. Cahan WG. Excision of melanoma metastases to lung: problems in diagnosis and management. Ann Surg. 1973;178(6):703-9.

9. Wilson RW, Moran CA. Primary melanoma of the lung: a clinicopathologic and immunohistochemical study of eight cases. Am J Surg Pathol. 1997;21(10):1196-202.

10. Azuma Y, Ono H, Kawabe K, Yanagimoto R, Suruda T, Minakata Y. Primary pulmonary melanoma diagnosed by semi-rigid thoracoscopy. Thorac Cancer. 2018;9(11):1528-9.

11. Kyriakopoulos C, Zarkavelis G, Andrianopoulou A, Papoudou-Bai A, Stefanou D, Boussios S, et al. Primary pulmonary malignant melanoma: report of an important entity and literature review. Case Rep Oncol Med. 2017;2017:8654326.

12. Ost D, Joseph C, Sogoloff H, Menezes G. Primary pulmonary melanoma: case report and literature review. Mayo Clin Proc. 1999;74(1):62-6.

13. Watanabe M, Yamamoto H, Hashida S, Soh J, Sugimoto S, Toyooka S, et al. Primary pulmonary melanoma: a report of two cases. World J Surg Oncol. 2015;13:274.

14. Feng $Y$, Zhao J, Yang Q, Xiong W, Zhen G, Xu Y, et al. Pulmonary melanoma and "crazy paving" patterns in chest images: a case report and literature review. BMC Cancer. 2016;16:592.

15. Maeda R, Isowa N, Onuma H, Miura H, Tokuyasu H, Kawasaki Y. Primary malignant melanoma of the lung with rapid progression. Gen Thorac Cardiovasc Surg. 2009:57(12):671-4.

16. Peng J, Han F, Yang T, Sun J, Guan W, Guo X. Primary malignant melanoma of the lung: a case report and literature review. Medicine (Baltimore). 2017 96(46):e8772.

17. Petersen RP, Hanish SI, Haney JC, Miller CC 3rd, Burfeind WR Jr, Tyler DS, et al. Improved survival with pulmonary metastasectomy: an analysis of 1720 patients with pulmonary metastatic melanoma. J Thorac Cardiovasc Surg. 2007;133(1):104-10.

18. Bajetta E, Del Vecchio M, Bernard-Marty C, Vitali M, Buzzoni R, Rixe O, et al. Metastatic melanoma: chemotherapy. Semin Oncol. 2002;29(5):427-45.

19. Yabuki H, Kuwana K, Minowa M. Resection of primary malignant lung melanoma: a case report. Asian Cardiovasc Thorac Ann. 2018;26(9):710-2.

20. Ascierto PA, Minor D, Ribas A, Lebbe C, O'Hagan A, Arya N, et al. Phase II trial (BREAK-2) of the BRAF inhibitor dabrafenib (GSK2118436) in patients with metastatic melanoma. J Clin Oncol. 2013;31(26):3205-11.

21. Long GV, Menzies AM, Nagrial AM, Haydu LE, Hamilton AL, Mann GJ, et al. Prognostic and clinicopathologic associations of oncogenic BRAF in metastatic melanoma. J Clin Oncol. 2011;29(10):1239-46.

22. Flaherty $K T$, Robert $C$, Hersey $P$, Nathan P, Garbe C, Milhem M, et al. Improved survival with MEK inhibition in BRAF-mutated melanoma. N Engl J Med. 2012:367(2):107-14.

23. Yun S, Vincelette ND, Green MR, Wahner Hendrickson AE, Abraham I. Targeting immune checkpoints in unresectable metastatic cutaneous melanoma: a systematic review and meta-analysis of anti-CTLA-4 and antiPD-1 agents trials. Cancer Med. 2016;5(7):1481-91.

24. Reed RJ 3rd, Kent EM. Solitary pulmonary melanomas: two case reports. J Thorac Cardiovasc Surg. 1964;48:226-31.

\section{Publisher's Note}

Springer Nature remains neutral with regard to jurisdictional claims in published maps and institutional affiliations.

Ready to submit your research? Choose BMC and benefit from:

- fast, convenient online submission

- thorough peer review by experienced researchers in your field

- rapid publication on acceptance

- support for research data, including large and complex data types

- gold Open Access which fosters wider collaboration and increased citations

- maximum visibility for your research: over $100 \mathrm{M}$ website views per year

At $\mathrm{BMC}$, research is always in progress.

Learn more biomedcentral.com/submissions 